\title{
The Effectiveness Of Routine Physiotherapy With And Without Neuromobilization In Patients With Shoulder Impingement Syndrome On Pain And Functional Disability; A Randomized Control Clinical Trial
}

\author{
Muhammad Akhtar ( $\square$ a.hunjra@gmail.com ) \\ Social Security Hospital \\ Hossein Kirimi \\ The University of Lahore - New Campus \\ Syed Amir Gilani \\ The University of Lahore - New Campus \\ Ashfaq Ahmad \\ The University of Lahore - New Campus \\ Asim Raza \\ The University of Lahore
}

\section{Research article}

Keywords: shoulder impingement, neuromobilization, functional disability.

Posted Date: December 2nd, 2019

DOI: https://doi.org/10.21203/rs.2.17627/v1

License: (c) (7) This work is licensed under a Creative Commons Attribution 4.0 International License. Read Full License

Version of Record: A version of this preprint was published at BMC Musculoskeletal Disorders on November 21st, 2020. See the published version at https://doi.org/10.1186/s12891-020-03787-0. 


\section{Abstract}

Background: Neuromobilization (NM) includes neurophysiological parameters that vary between clinicians. This randomized controlled trial aimed to investigate the NM on the outcomes of participants with shoulder impingement syndrome (SIS) following treatment sessions (base line to follow up). Study design: Single blinded randomized control clinical trial. Methods: Patients (80) with shoulder impingement syndrome (SIS) were asked to participate in this trial. At the first session, participants were randomly assigned to either control group (40) or experimental group (40). After the baseline assessment routine physiotherapy was executed for both groups, while NM was provided to experimental group. Pain and functional disability score were evaluated on baseline, post treatment and after follow up. Pain was considered as primary out come and functional disability score as secondary outcome. Improvement was evaluated at post treatment and follow up. Differences in outcome between groups were evaluated with clinical improvement. Results: The experimental group compared with control group at 11th week had lower mean pain score 2.15(1.66-2.64) vs 4.90(4.41-5.40); between group difference, $1.82 ; 95 \%(\mathrm{Cl}),-2.38$ to $-1.25 ; \mathrm{P} \otimes 0.001$ and Partial $\otimes 2=0.33$, similarly functional disability score $28.58(27.32-29.83)$ vs 20.10(18.84-21.36); between group difference, $5.62 ; 95 \% \mathrm{Cl},(4.32-6.92) ; \mathrm{P} \otimes 0.001$ and Partial $\otimes 2=0.49$. Over all pain and functional disability score were improved among experimental group relative to control group at 11th week. Conclusion: In an experimental setting, the delivery of neuromobilization leads to significantly different outcomes in participants than in control group. Studies are still required to explore the mechanisms underlying neuromobilization effects. Trial registration: IRCT20190121042445N1, Registered 19 February 2019. Key words: shoulder impingement, neuromobilization, functional disability.

\section{Background}

The subacromial impingement syndrome (SIS) consists of the rotator cuff tendonitis and bursitis of the shoulder (1). The SIS includes the inflammation of the supraspinatus tendon inside the anteroinferior junction of the acromion and the greater tuberosity of the humerus. SIS is categorized by severe acute pain which increases during overhead activities as well as at night sleeping on affected side (2).

SIS comprises of three stages, the 1st stage is defined by edema and hemorrhage of the subacromial bursa and rotator cuff; it has been detected in patients where age group is less than 25 years. The next stage indicates irreversible changes, which are fibrosis combine with tendinopathy of the rotator cuff. This has been observed among patients who are up to 25 to 40 years of age. At III stage impingement is evident by more severe changes, like partial or complete tears of the rotator cuff, mostly observed among patients who are above 40 years age (3) (4).

The concept of neuromobilization (NM) includes connection between mechanics and physiology of the nervous system in which interactions occur both ways and can be beneficial intensely in pain management.

Mechanical management may therefore be used to augment physiology in the nervous system. NM sequencing is the activity of set of specific component of body movements so as to get particular mechanical events in the nervous system, which is to that specific of component movements (5).

In a review article of Monica A Matocha et al. 2015, it has already been observed that there are three theories projected for the local etiological origin of tendon pain: 1-mechanical, 2-vascular and 3- neural (6) (7).

Mechanical and vascular theories are regularly used for the treatment of tendon pain. The neural component is over looked due to poor outcomes among patients with tendinopathy. Monica A Matocha et al. highlighted neural involvement in patients with tendon pain and discussed the role of NM for tendon pain (8). The utilization of neurodynamics may be important for the treatment purposes in patients who suffer with tendonopathies which has neural component (6) (9) .

Objective: To compare the effects of NM technique and routine physiotherapy on pain and functional disability in shoulder impingement syndrome.

\section{Methods}

\section{Trial design:}

The model of study was single blinded randomized controlled clinical trial. This controlled trial used a parallel design where patients were allotted by implementation by 1:1 ratio in two groups(one experimental group as well as other control group). The trial is reported to the CONSORT 2010 statement (10). These patients had gone through a complete systemic physical examination, that includes the whole neurologic and musculoskeletal assessments and the following participants had excluded from the above study that had gone through 
the shoulder surgery, shoulder injury, history of trauma, shoulder joint dislocation A.C joint pathology, cervical radioculopathy and other systemic diseases. The patients who are diagnosed of having positive upper limb tension test (11) along with Neer (3) (4), Hawkins Kennedy (12) Empty Can (12), painful arc and cross body adduction test (13) can undergo the specific treatment to get desired results.

\section{Randomization:}

Randomization was performed by using computer generated random sequence table before the above assessment. Individuals, sequentially numbered index cards with the random assignment were prepared for treatment. The index cards were folded and placed in sealed and opaque envelopes. After the baseline examination, the participants were randomly assigned to receive routine physiotherapy or routine physiotherapy combined with neuromobilization.

One of the experienced staff members generated the random allocation sequence.

\section{Blinding:}

An independent assessor, who specialized in musculoskeletal injuries with more than five year experience of dealing patients with shoulder injury, was masked to the group for the allocation of the patients for treatment.

\section{Participants:}

Eighty clinically analyzed patients of SIS had visited physical therapy department and enrolled for specific analysis. The study was described to all patients and informed consent was taken from them. This very consent process and form was approved by University Of Lahore Institutional Review Board before initial random selection of patients. These participants got admitted among patients who were visiting physiotherapy unit at Social Security Hospital Gujranwala.

\section{Procedures:}

The assessment of the patients occurred by a physiotherapist who had seven years long experience in his department by implementing previous history and examination. Demographic details, visual analogue scale (VAS) of pain and functional disability by University of California at Los Angeles rating score (UCLA) had been noted.

Aforementioned findings were kept hidden. Patients remained unnamed during the procedure. It was imparted information to them there were no harm of this given procedure it was further imparted they could discontinue it at any time during this procedure.

VAS was used to evaluate the severity of pain and it was considered as primary outcome of the specific study. A constant scale had been employed to inquire the patients about the shoulder pain during the activity and to classify it by indicating on a 10-mm line; it was connected "no pain" and the "worst pain you have ever felt". This is common method of evaluating severity of pain. The given study findings have indicated that the VAS has high reliable as well as valid method to assess pain (14). UCLA score was assessed at base line, post treatment and after $1^{\text {st }}$ follow up (15).

\section{Interventions:}

The patients were allocated into two groups; 1-Routine physiotherapy 2-Routine physiotherapy and NM. The patients have been under gone the treatment only for 3 times during a week which has been consisting of fifteen sessions. The patients were evaluated at baseline, after last treatment ( $5^{\text {th }}$ week) and after $1^{\text {st }}$ follow up ( $11^{\text {th }}$ week). For ethical issues, as routine physiotherapy combined with NM group proved to get better results at the end of our interventions, we gave the control group with NM after the $1^{\text {st }}$ intervention (16).

\section{Routine Physical Therapy:}

The routine Physiotherapy consisted of pulsed Short Wave Diathermy (SWD) with frequency $27.12 \mathrm{MHZ}$, Ultrasonic Therapy(US) with frequency $1.0 \mathrm{MHZ}$ and intensity $1.45 \mathrm{w} / \mathrm{cm}^{2}$ (17) and Transcutaneous Electrical Nerve Stimulator (TENS) 2-200 HZ with output current < $20 \mathrm{Ma}$ width $200 \mu$ seconds along with continuous mode. Exercises comprised were shoulder strengthing and stretching exercises were performed for $5 \mathrm{sec}$ with 10 repetitions (18). See exercises in Table-II

\section{Neuromobilization:}

Mechanical management may therefore be used to augment physiology in the nervous system. NM sequencing is the activity of set of specific component of body movements so as to get particular mechanical events in the nervous system, which is to that specific of 
component movements (5).NM was applied by using Butler's recommendations (19).

Initially, the patient performed neural sliders and gradually progressed to neural tensioners. Neural sliders consisted of cervical lateral flexion movement, toward the involved side, simultaneously with elbow flexion and extension movements. While moving the head in to cervical lateral flexion the elbow was extended. When the elbow began to flex, the cervical spine was returned to neutral position. Neural tensioners are performed to create tension in the nerve to get the desired results. The tension position is not held for a length of time, but is released by extending the elbow and returning the cervical spine to neutral. Once the patient had pushed slight pain or discomfort at any point (20). NM technique was performed for $5 \mathrm{sec}$ with 10 repetitions to control the pain and improve the functional disability score to relive the pain. See table-II

\section{Outcome measures:}

Patients were assessed at baseline, after post treatment ( $5^{\text {th }}$ week) and after 1 st follow up ( $11^{\text {th }}$ week) on VAS pain scale ( 0 no pain 10 maximum pain). (14) Pain was considered as primary outcome.

UCLA score was assessed at baseline, on post treatment ( $5^{\text {th }}$ week) and at 1 st follow up (11 $1^{\text {th }}$ week) (15). UCLA score was considered as secondary outcome.

\section{Sample size:}

Sample size calculation was derived from Abeer A et al's paper (21).

According to clinical trials, the sample size estimation formula was implemented (22).

Sample size $=\frac{2 \mathrm{SD}^{2}\left(\mathrm{Z}_{\alpha / 2}+\mathrm{Z}_{\beta}\right)^{2}}{\mathrm{~d}^{2}}$

Where $S D=$ Standard deviation $=14.08, Z_{1^{-}{ }^{-} \mathrm{a} / 2}$ is type 1 error $=1.96, Z_{\beta}=0.84, d=\mu_{2} \mu_{1}=10.7$.

Based on this a total sample size of around 80 (experimental $=40$, controls $=40$ ) was calculated to be an adequate mean to reach the conclusion.Considering a loss of $20 \%$ follow-up, at least $80 \%$ patients followed the treatments (23). An experimental group and a control group were recruited which were based on the inclusion criteria for this study (Figure. 1). Both the groups of patients were selected by regularly visiting the physiotherapy department at Social Security Hospital Gujranwala.

\section{Data analysis:}

\section{Statistical analysis}

The data were analyzed by using SPSS 22.0 programme.

Qualitative data was presented in frequencies and percentages while mean and S.D was calculated for Quantitative data. Line chart was drawn at various times in weeks during the treatment vs pain score and UCLA score.

Repeated measure ANOVA was applied among both the group to compare average pain and UCLA score different times (baseline, $5^{\text {th }}$ week, $11^{\text {th }}$ week). The confidence level of $95 \%$ was used as well as $p$ value $\leq 0.05$ was considered as significant.

\section{Primary outcome analysis}

Repeated measure ANOVA was applied among both the groups to compare the average pain score different times $\left(\right.$ baseline, $5^{\text {th }}$ week, $11^{\text {th }}$ week). The confidence level of $95 \%$ was used as well as $p$ value $\leq 0.05$ was considered as significant.

\section{Secondary outcome analysis}

UCLA was identified as secondary outcome. Repeated measure ANOVA was applied among the groups to compare the average UCLA score different times (baseline, $5^{\text {th }}$ week, $11^{\text {th }}$ week). The confidence level of $95 \%$ was used as well as $p$ value $\leq 0.05$ was considered as significant. 


\section{Results}

\section{Recruitment}

The above study was started on September 2016 and last follow up was occurred on March 2018 and then trial ended. It was considered regarding the number of the participants in each group laid within the range estimated (40 each group). Data was collected at Social Security Hospital Gujranwala.

\section{Participant flow}

One hundred and twenty participants had been observed for eligibility process at the time of September 2016 till February 2018, among 30 participants had not been found eligible. The ineligible participants were excluded from the given study and had been given the routine physiotherapy treatment. The reasons for ineligibility of the patients are presented in Fig. 1, out of 90 eligible participants, 10 had further excluded as they denied being part of study. The above mentioned 10 participants were also given the routine physiotherapy treatment. The rest of 80 participants divided an experimental group and a control group. On $11^{\text {th }}$ week follow-up, 12 participants left the study and 68 patients had completed the whole evaluation. The cause of withdrawal are provided in Figure 1.The participants who did not complete treatment on $11^{\text {th }}$ week follow-up measurements had been included for further analysis. The missing values of dropped out patients were included in the current analysis by using last observation carried forward (LOCF).

The experimental sheet is presented through figure 1.

\section{The baseline demographic profile}

The baseline characteristics are presented in table-I. Demographic profile shows that most of the patients suffering from SIS are female, who were (32) in experimental group and 26 in control group. It was also observed that mostly patients falling in type - 1 Neer classification. See table 1

\section{Results of primary outcome}

The results of primary outcome are reported in table-III. For the control group, average Shoulder pain was $6.78 \pm 1.14,5.0250 \pm 1.79$ and $4.90 \pm 1.58$ at base line, $5^{\text {th }}$ week and $11^{\text {th }}$ week respectively. Similarly, average shoulder pain for experimental group (with NM) was $6.95 \pm 1.28,2.15 \pm 1.87$ and $2.15 \pm 1.55$ at base line, 5 th week and $11^{\text {th }}$ week respectively. Above mentioned results show the clear difference in average shoulder pain between two groups and shoulder pain of experimental group was more improved as compared to control group at different stages.

\section{Results of secondary outcome}

The results of secondary outcome are reported in table-IV. For the control group, average UCLA score were $14.50 \pm 2.37,19.07 \pm 4.43$ and $20.10 \pm 4.08$ at base line, $5^{\text {th }}$ week and $11^{\text {th }}$ week respectively. Similarly, mean UCLA score for experimental group (with NM) were $14.05 \pm 2.59,27.90 \pm 4.13$ and $28.58 \pm 3.89$ at base line, 5 th week and $11^{\text {th }}$ week respectively. Above mentioned results show the clear difference in mean shoulder UCLA score between both groups and UCLA score of experimental group was more improved as compared to control group at different stages.

\section{Outcomes and estimation}

The experimental group compared with control group at $11^{\text {th }}$ week had lower mean pain score $2.15(1.66-2.64)$ vs 4.90(4.41-5.40); between group difference, $1.82 ; 95 \%$ confidence interval $(\mathrm{Cl}),-2.38$ to $-1.25 ; \mathrm{P} \otimes 0.001$ and Partial $\rrbracket^{2}=0.33$ shown in table-V. Similarly functional

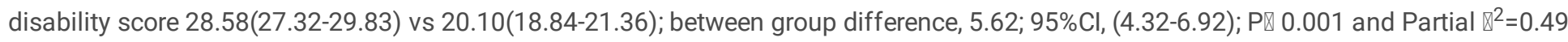
shown in table-VI. Over all pain and functional disability score were improved among experimental group relative to control group at $11^{\text {th }}$ week.

\section{Harms}

In experimental group two patients were dropped out on $11^{\text {th }}$ week because they were not satisfied with the treatment and one patient dropped out due to worsening of the symptoms. Similarly in control group four patients dropped out due dissatisfaction given by the treatment. 


\section{Discussion}

\section{The results of routine physiotherapy with and without NM during the pain}

The results of the current study demonstrated remarkable improvement of pain among the two groups with SIS at 5 th week and at $11^{\text {th }}$ week follow-ups. So, it was greater betterment in the experimental group as compared to the control group. The results of the study of Pritam Daka prove the fact that NM has fruitful effects in mitigating the pain by restoring neurodynamics properties in upper limb. Robert $\mathrm{J}$ Nee et al study has found immediate relief of pain in arm with no evidence of harmful effects and future research are recommended to check long term effects of NM on pain(24).

It was observed that the use of neuromobilization has shown beneficial effect for short period over pain (25).

The results of our study are also in agreement with Pritam Deka,who explored that neuromobilization is effective treatment for pain and when neuromobilization and TENS combined was used then more effective results were found on cervical radiculopathy (26).

The current study found the results to be similar to those of Matocha et al who found that pain intensity decreased weekly basis as decreased in our study on $5^{\text {th }}$ and $11^{\text {th }}$ week but further research is needed to help clinicians in making education decision for implementing these techniques in to clinical practice(20).

From the available clinical research from the study of Mark T. Wash et al, it does not indicate clear findings for the appropriate duration, dosage, intensity, or type of exercise to be employed; so, there is clear evidence of NM as a useful treatment strategy (11).

The following a systemic review of the given literature, which examined the efficacy of neuromobilization, 10 RCTs has discussed in 11 studies. The majority of these studies have concluded the positive therapeutic effects using the neuromobilization(27).

\subsection{The effects of routine physiotherapy with and without NM on UCLA score}

The results of the current study have indicated statistically improvement on UCLA scores between the two groups of participants with SIS at $5^{\text {th }}$ week and at $11^{\text {th }}$ week follow-up. The final findings of this study finally prove NM has useful effects on improving UCLA score.

The given findings of our study confirm this NM is effective in improving UCLA score on $5^{\text {th }}$ week and $11^{\text {th }}$ week follow up. The similar results were also noted in the study of Richard F. Ellis et al. who found that shoulder pain and disability scores were significantly improved in the experimental group(27).

\subsection{Possible mechanisms leading to relief of symptoms}

Rees JD et al. (2006) observed mechanical, vascular and neural theories which have proposed for tendinopathy, which point out the potential appropriate use of NM. The use of NM has the potential to lessen the perception of pain. The movement of the nervous system during NM may restore axoplasm flow, restoring nutrients to the nerves. The restoration of nerve function may then lessen sensitivity (i.e ion channels) to the area and restore normal blood flow to the tendon (7).

Physiological explanation of our conclusion is that a nerve which closely passes to a joint is mostly kept in a tunnel or it is attached with collagen fibres or fascia to the nearby musculoskeletal components. Nerves move side by side with in the upper limb hence the neuromobilization given during management cause break of the cross linkages. The nerves mobilize towards the moving joint. The larger amplitude of movements at a specific joint, more of the sliding phenomenon of the nerve takes place at the specific joint. So, large amplitude movements are maintained the mobility of the joint and the nerve. Nervous tissue mobilization sustains to re-establish the dynamic equilibrium of neural tissue and it normalize the physiological function (5). The vesicle cluster increased the response to applied stretch (28). The possible effect of stretch on axons is the improved ion flux in stretch sensitive ion channels (Glogauer $\mathrm{M}$ et al.). The mechanical stimulation using at low frequency, low intensity ultrasound are indicated to arouse neurons in mouse brain by activating voltage gated sodium and calcium channels. The slow elongation can cause structural changes in myelin sheath, axon regeneration, deposition of endoneurial collagen (Hara $Y$ et al. 2003). The nodes of ranvier can open further as it causes the Schmidt- Lanterman clefts which affects the levels of local cytoplasm (Butler 199) (28).

Neurophysiological result of spinal manipulations has earlier shown in the literature of 20 studies. These studies point out that mobilization of nervous tissue enhances peripheral blood flow, using a physiological shift toward parasympathetic domination (Kornberg). The neurophysiological results of spinal manipulations are reported in the literature(29, 30). 
Different neuromuscular responses (like hypoalgesia, the motor neuron pool activity, afferent discharge and changes in the mobility of muscle) associated with neuromobilization indirectly indicates the spinal cord mediated effect of the NM. Neuromobilization had an quick hypoalgesic effect on C-fibre mediated pain perception, as not on A-delta fibre mediated pain perception (31).

Another reason of more improvement of pain in the experimental group may be shown the restoration of mobility due to the biomechanical effects which are inter-linked with NM (31).

\section{Limitations}

There are several limitations to the current study that warrant the further discussion. First, overall sample size in our study is lower than the other major training studies in the literature(32).

However, benefits of a smaller sample size were the ability to supervise the exercises program and more closely interaction with patients on a daily basis during the exercise sessions for better results. In particular, the adherence to the prescribed exercise intensity and program was excellent for both exercise treatment groups. Second, the present study (11weeks) was also relatively reasonable in duration compared to previous training investigations(33)

Nevertheless, the significant improvements in pain and functional disability score was found in the present study which indicated that a 11 weeks exercise training period was a sufficient time frame to demonstrate significant training effects. Future research is needed to confirm the possibility of additional improvements in pain and functional disability score following an exercise training program similar in characteristics to the present study but for prolonged duration.

\section{Generalizability}

\section{Clinical considerations for effective neuromobilization in clinical treatment}

After recognizing the close relationship between physical capacities and life style, it is likely to be declared that implementation of effective NM proves standard part of the treatment for SIS patients will decrease shoulder pain and improve function. This study shows that NM is not only feasible as a part of the treatment, but it also has a large effect size and efficient for all the times.

SIS patients who suffer from many challenges, so it is important to recognize that their shoulder pain and functional disability score constitute an important part of overall health and daily tasks. Since shoulder impingement syndrome are known to be important key factor for daily life activities in term of pain and function. Today's treatment also appears to have very limited results, if pain and function effects. Importantly, this study, as well as neuromobilization regimes is feasible and safe to carry out within this patient group.

Trial Registration: IRCT20190121042445N1.

\section{Conclusion}

It is concluded that neuromobilization technique advocated significant improvement over the time in pain and functional disability score in experimental group. The findings of current study indicated that it is a remarkable reduction in severity of pain and improvement in functional disability with neuromobilization technique as compared to routine physiotherapy.

\section{Abbreviations}

1. SIS (Shoulder Impingement Syndrome)

2. VAS (Visual Analogue Scale)

3. SWD (Short Wave Diathermy)

4. US (Ultra Sonic)

5. TENS ( Transcutaneous Electrical Nerve Stimulation)

6. NM (Neuromobilization)

7. ANOVA (Analysis of Variance)

8. C Joint (Acromio Clavicular Joint)

9. D (Standard Deviation)

10. I(Confidence Interval) 
11. University of California at Los Angeles rating score (UCLA)

12. SPSS (Statistical Package for Social Sciences)

13. LOCF (last observation carried forward)

\section{Declarations}

\section{- Ethics approval and consent to participate}

Ethical approval was taken from University of Lahore, Ethical review committee Professor Dr. Syed Amir Gilani Dean Faculty of Allied Health Sciences is Chairman of committee with reference No. IRB-UOL-FAHS/00238-II. The written informed consent was obtained from all participants with the following consent statement.

\section{"I have read this consent form and agreed to participate in this study. I give my consent to enroll myself in this study" \\ Participant's signature—Date}

\section{- Consent to publish}

The written consent was obtained from all participants to publish my article and images.

\section{- Availability of data and materials}

- The data sets used and/or analyzed during the current study are available from the corresponding author on reasonable request.

- Competing interests

The authors declared that Professor Dr Amir Gilani is Chairperson of ethical review committee and also coauthor of our study.

\section{- Funding}

There is no funding source for this article publication.

\section{- Authors' contributions}

- MA: Study conception, design and analysis, interpretation of data and drafting of manuscript.

- HK: Literature search, study design, analysis and interpretation of data.

- AG: Revision of the manuscript and critical appraisal for final approval to be published.

- AA: Drafting and data interpretation.

- AR: Statistical analysis and interpretation.

All authors have read and approved the manuscript.

\section{- Acknowledgement}

This study was a part of Ph.D Physical therapy project (the effectiveness of routine physiotherapy with and without neuromobilization in patients with shoulder impingement syndrome on pain and functional disability) supported by the University of Lahore, Lahore, Punjab, Pakistan. Authors are extremely thankful to all volunteers and subjects who participated in this study.

\section{References}

1. Gebremariam L, Hay EM, van der Sande R, Rinkel WD, Koes BW, Huisstede BM. Subacromial impingement syndrome-effectiveness of physiotherapy and manual therapy. Br J Sports Med. 2014;48(16):1202-8.

2. Koh E-K, Jung D-Y. Effects of Modified Cross-body Stretching on Range of Motion in Glenohumeral Joint. Journal of Korean Society of Physical Medicine. 2015;10(4):1-7.

3. Neer Cn. Impingement lesions. Clin Orthop. 1983;173(70):7.

4. Ark JW, Flock TJ, Flatow EL, Bigliani LU. Arthroscopic treatment of calcific tendinitis of the shoulder. Arthroscopy: The Journal of Arthroscopic \& Related Surgery. 1992;8(2):183-8.

5. Shacklock M. Clinical neurodynamics: a new system of musculoskeletal treatment: Elsevier Health Sciences; 2005. 
6. Kaux J-F, Forthomme B, Le Goff C, Crielaard J-M, Croisier J-L. Current opinions on tendinopathy. Journal of sports science \& medicine. 2011;10(2):238.

7. Rees J, Wilson A, Wolman R. Current concepts in the management of tendon disorders. Rheumatology. 2006;45(5):508-21.

8. Matocha MA, Baker RT, Nasypany AM, Seegmiller JG. Effects of Neuromobilization on Tendinopathy: Part I. International Journal of Athletic Therapy and Training. 2015;20(2):36-40.

9. Cook J, Purdam CR. Is tendon pathology a continuum? A pathology model to explain the clinical presentation of load-induced tendinopathy. British journal of sports medicine. 2009;43(6):409-16.

10. Schulz KF, Altman DG, Moher D. CONSORT 2010 statement: updated guidelines for reporting parallel group randomised trials. BMC medicine. 2010;8(1):18.

11. Walsh MT. Upper limb neural tension testing and mobilization: fact, fiction, and a practical approach. Journal of hand therapy. 2005;18(2):241-58.

12. Sallis R. Examination skills of the musculoskeletal system. American Academy of Family Physicians Retrieved on. 2017;9(01).

13. Park HB, Yokota A, Gill HS, El Rassi G, McFarland EG. Diagnostic accuracy of clinical tests for the different degrees of subacromial impingement syndrome. JBJS. 2005;87(7):1446-55.

14. McCaffery M, Pasero C. Practical nondrug approaches to pain. Pain: Clinical manual. 1999:399-427.

15. Amstutz HC, Sew AH, Clarke IC. UCLA anatomic total shoulder arthroplasty. Clinical orthopaedics and related research. 1981(155):720.

16. Friedman LM, Furberg CD, DeMets DL, Reboussin DM, Granger CB. Basic study design. Fundamentals of clinical trials: Springer; 2015. p. 89-121.

17. Benjaboonyanupap D, Paungmali A, Pirunsan U. Effect of therapeutic sequence of hot pack and ultrasound on physiological response over trigger point of upper trapezius. Asian journal of sports medicine. 2015;6(3).

18. Michener LA, Walsworth MK, Burnet EN. Effectiveness of rehabilitation for patients with subacromial impingement syndrome: a systematic review. Journal of hand therapy. 2004;17(2):152-64.

19. Butler D, Gifford L. The concept of adverse mechanical tension in the nervous system part 1: testing for "dural tension". Physiotherapy. 1989;75(11):622-9.

20. Matocha MA, Baker RT, Nasypany AM, Seegmiller JG. Effects of Neuromobilization on Tendinopathy: Part II. International Journal of Athletic Therapy and Training. 2015;20(2):41-7.

21. Yamany AA, Salim SE. Efficacy of low level laser therapy for treatment myofascial trigger points of shoulder pain. World Applied Sciences Journal. 2011;12(6):758-64.

22. Charan J, Biswas T. How to calculate sample size for different study designs in medical research? Indian journal of psychological medicine. 2013;35(2):121.

23. Dunning JR, Cleland JA, Waldrop MA, Arnot C, Young I, Turner M, et al. Upper cervical and upper thoracic thrust manipulation versus nonthrust mobilization in patients with mechanical neck pain: a multicenter randomized clinical trial. Journal of Orthopaedic \& Sports Physical Therapy. 2012;42(1):5-18.

24. Nee RJ, Butler D. Management of peripheral neuropathic pain: integrating neurobiology, neurodynamics, and clinical evidence. Physical Therapy in Sport. 2006;7(1):36-49.

25. Efstathiou MA, Stefanakis M, Savva C, Giakas G. Effectiveness of neural mobilization in patients with spinal radiculopathy: a critical review. Journal of bodywork and movement therapies. 2015;19(2):205-12.

26. Deka P. THE COMBINED EFFICACY OF NEURAL MOBILIZATION WITH TRANSCUTANEOUS ELECTRICAL NERVE STIMULATION (TENS) VERSUS NEURAL MOBILIZATION ALONE FOR THE MANAGEMENT OF CERVICAL RADICULOPATHY 2013.

27. Ellis RF, Hing WA. Neural mobilization: a systematic review of randomized controlled trials with an analysis of therapeutic efficacy. Journal of manual \& manipulative therapy. 2008;16(1):8-22.

28. Siechen S, Yang S, Chiba A, Saif T. Mechanical tension contributes to clustering of neurotransmitter vesicles at presynaptic terminals. Proceedings of the National Academy of Sciences. 2009;106(31):12611-6.

29. George SZ, Bishop MD, Bialosky JE, Zeppieri G, Robinson ME. Immediate effects of spinal manipulation on thermal pain sensitivity: an experimental study. BMC Musculoskeletal disorders. 2006;7(1):68.

30. Vicenzino B, Collins D, Benson H, Wright A. An investigation of the interrelationship between manipulative therapy-induced hypoalgesia and sympathoexcitation. Journal of manipulative and physiological therapeutics. 1998;21(7):448-53. 
31. Beneciuk JM, Bishop MD, George SZ. Effects of upper extremity neural mobilization on thermal pain sensitivity: a sham-controlled study in asymptomatic participants. Journal of Orthopaedic \& Sports Physical Therapy. 2009;39(6):428-38.

32. Ruiz JR, Sui X, Lobelo F, Lee D-c, Morrow JR, Jackson AW, et al. Muscular strength and adiposity as predictors of adulthood cancer mortality in men. Cancer Epidemiology and Prevention Biomarkers. 2009;18(5):1468-76.

33. Hill TR, Gjellesvik TI, Moen PMR, Tørhaug T, Fimland MS, Helgerud J, et al. Maximal strength training enhances strength and functional performance in chronic stroke survivors. American journal of physical medicine \& rehabilitation. 2012;91(5):393-400.

\section{Tables}

Table-I List of exercises performed under experimental and routine physiotherapy group.

xperimental group ( stretching and strengthing exercises + euromobilization)

\section{1) STRETCHING EXERCISES}
a) Shoulder external rotation stretch
b) Cross body posterior stretch
C) Stretch for anterior aspect of shoulder
d) Shoulder flexion stretch

2) STRENGTHING EXERCISES
a) Chair press
b) Restricted scapular retraction
C) Restricted scapular protraction
d) Shoulder abduction "Scaption" $\left(0^{\circ}-90^{\circ}\right)$ with theraband
e) Shoulder scapular extension with theraband

\section{3) NEUROMOBILIZATION EXERCISES}
a) Neural slider technique
b) Neural tensioner technique

Routine physiotherapy group (Stretching and strengthing exercises)

1) STRETCHING EXERCISES
a) Shoulder external rotation stretch
b) Cross body posterior stretch
C) Stretch for anterior aspect of shoulder
d) Shoulder flexion stretch

2) STRENGTHING EXERCISES
a) Chair press
b) Restricted scapular retraction
C) Restricted scapular protraction
d) Shoulder abduction "Scaption" $\left(0^{\circ}-90^{\circ}\right)$ with theraband
e) Shoulder scapular extension with theraband

Table-II Comparison of Scio-demographic data of the patients 


\begin{tabular}{|c|c|c|c|c|c|c|c|c|c|}
\hline \multicolumn{2}{|c|}{ ble } & $\begin{array}{l}\text { Experimental } \\
\text { Group } \\
(\mathrm{N}=40)\end{array}$ & $\begin{array}{l}\text { Control } \\
\text { Group } \\
(\mathrm{N}=40)\end{array}$ & P-Value & \multicolumn{2}{|l|}{$\begin{array}{l}\text { Age } \\
\text { Years }\end{array}$} & $36.38 \pm 8.93$ & $34.40 \pm 9.32$ & 0.336 \\
\hline \multirow[t]{2}{*}{$\mathrm{er}$} & Male & $8(20 \%)$ & $14(32.4)$ & \multirow[t]{2}{*}{0.133} & \multirow[b]{3}{*}{$\begin{array}{l}\text { Type 2: } \\
\text { Pain at } \\
60^{\circ}-70^{\circ}\end{array}$} & \multirow[b]{3}{*}{$6(15.0 \%)$} & \multirow[b]{3}{*}{$2(5.0 \%)$} & & \\
\hline & Female & $32(80 \%)$ & $26(65 \%)$ & & & & & & \\
\hline \multirow{3}{*}{-} & $\begin{array}{l}\text { Type 1: Pain at } \\
90^{\circ}\end{array}$ & $34(85.0 \%)$ & $38(95.0 \%)$ & \multirow[t]{2}{*}{0.136} & & & & & \\
\hline & \multirow{3}{*}{$\begin{array}{l}\text { Pain/Discomfort } \\
\text { on Palpation }\end{array}$} & A.C Joint & $11(27.5 \%)$ & & \multirow[t]{2}{*}{$13(32.5 \%)$} & \multirow[t]{3}{*}{0.375} & \multirow[b]{2}{*}{$5(12.5 \%)$} & & \\
\hline & & & & $2(5.0 \%)$ & & & & & \\
\hline $\begin{array}{l}\mathrm{S} \\
\mathrm{m}\end{array}$ & & $27(67.5 \%)$ & $22(55.0 \%)$ & & & & & & \\
\hline
\end{tabular}

I Comparison of base line and final values for VAS across 2 treatment groups with $\mathrm{P}$ value

\begin{tabular}{l|l|l|l|l|}
\hline urement & Group & Baseline value \pm SD & Final value on $11^{\text {th }}$ week \pm SD & P value \\
\hline \multirow{2}{*}{ TAS } & Control & $6.78 \pm 1.04$ & $4.9 \pm 1.58$ & \\
\cline { 3 - 5 } & Experimental & $6.95 \pm 1.176$ & $2.15 \pm 1.54$ & $\square 0.01$ \\
\hline
\end{tabular}

$\checkmark$ Comparison of base line and final values for UCLA across 2 treatment groups with P value

\begin{tabular}{l|l|l|l|l|}
\hline urement & Group & Baseline value \pm SD & Final value on $\mathbf{1 1}^{\text {th }}$ week \pm SD & P value \\
\hline CLA & Control & $14.5 \pm 2.37$ & $20.10 \pm 4.08$ & \\
\cline { 3 - 5 } & Experimental & $14.05 \pm 2.59$ & $28.57 \pm 3.89$ & $\square 0.01$ \\
\hline
\end{tabular}

$\checkmark$ Comparison of Mean difference (95\% CI) of between and within group comparison and Partial $\square^{2}$ with P value

\begin{tabular}{|c|c|c|c|c|c|c|}
\hline \multirow{2}{*}{\multicolumn{2}{|c|}{ ne Measures }} & \multicolumn{2}{|l|}{$\begin{array}{l}\text { Mean }(95 \% \\
\text { CI) } \\
\text { group Comparison }\end{array}$} & \multirow[t]{3}{*}{$\begin{array}{l}\text { Mean Difference ( } 95 \% \mathrm{Cl} \text { ) of Between group } \\
\text { Comparison by ANOVA (Experimental vs Control) }\end{array}$} & \multirow[t]{2}{*}{$\begin{array}{l}\text { Partial } \\
\square^{2}\end{array}$} & \multirow[t]{2}{*}{$\begin{array}{l}\text { P- } \\
\text { value }\end{array}$} \\
\hline & & Experimental group & Control group & & & \\
\hline \multirow{4}{*}{ ment } & Baseline & $6.95(6.60-7.30)$ & $6.78(6.42-7.13)$ & & \multirow{4}{*}{0.34} & \multirow{4}{*}{$<0.001$} \\
\hline & $5^{\text {th }}$ week & $2.15(1.60-2.71)$ & $5.03(4.46-5.59)$ & \multirow{3}{*}{$1.82(-2.38$ to- 1.25$)$} & & \\
\hline & & & & & & \\
\hline & $\begin{array}{l}11^{\text {th }} \\
\text { week }\end{array}$ & $2.15(1.66-2.64)$ & $4.90(4.41-5.40)$ & & & \\
\hline
\end{tabular}


VI Comparison of Mean difference (95\% CI) of between and within group comparison and Partial $\square^{2}$ with P value

\begin{tabular}{|c|c|c|c|c|c|}
\hline \multirow[t]{2}{*}{$\begin{array}{l}\text { ne } \\
\text { res }\end{array}$} & \multicolumn{2}{|l|}{$\begin{array}{l}\text { Mean (95\% } \\
\text { CI) } \\
\text { group Comparison }\end{array}$} & \multirow[t]{2}{*}{$\begin{array}{l}\text { Mean Difference ( } 95 \% \mathrm{Cl} \text { ) of Between group Comparison } \\
\text { by ANOVA (Experimental vs Control) }\end{array}$} & \multirow[t]{2}{*}{$\begin{array}{l}\text { Partial } \\
\square^{2}\end{array}$} & \multirow[t]{2}{*}{$\begin{array}{l}P \text { - } \\
\text { value }\end{array}$} \\
\hline & Experimental group & Control group & & & \\
\hline Baseline & $14.05(13.27-14.83)$ & $14.50(13.72-15.28)$ & \multirow{3}{*}{$5.62(4.32-6.92)$} & \multirow{3}{*}{0.49} & \multirow{3}{*}{$<0.001$} \\
\hline $5^{\text {th }}$ week & $27.90(26.55-29.25)$ & $19.08(17.73-20.42)$ & & & \\
\hline $\begin{array}{l}11^{\text {th }} \\
\text { week }\end{array}$ & $28.58(27.32-29.83)$ & $20.10(18.84-21.36)$ & & & \\
\hline
\end{tabular}

\section{Figures}

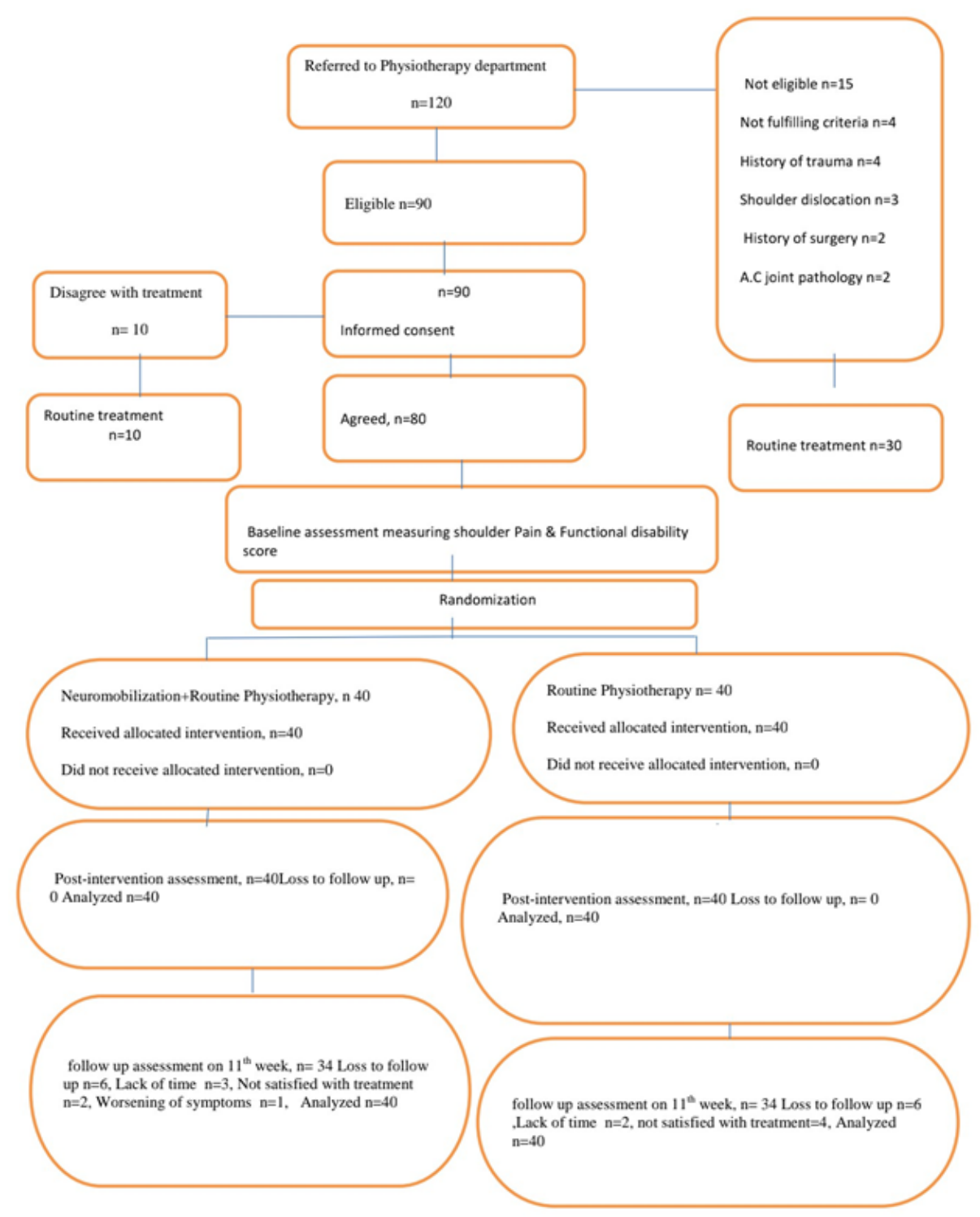

\section{Figure 1}

Flow sheet Diagram 


\section{Supplementary Files}

This is a list of supplementary files associated with this preprint. Click to download.

- CONSORT2010Checklist.pdf 